\title{
ANALYSIS OF MULTIPLE BIRTH RATES IN JAPAN \\ VI. QUADRUPLETS: BIRTH AND STILLBIRTH RATES
}

\author{
Yoko IMArZUMI ${ }^{1}$ and Eiji INOUYE ${ }^{2}$ \\ ${ }^{1}$ Institute of Population Problems, Ministry of Health and \\ Welfare, Tokyo 100, Japan \\ ${ }^{2}$ Institute for Developmental Research, Aichi Prefectural \\ Colony, Aichi 480-03, Japan
}

Summary Overall quadruplet birth rates per million deliveries were 1.14 and 3.29 during the period from 1955 to 1967 and in 1974, respectively. The higher quadruplet birth rate in 1974 might be attributed to higher proportion of mothers treated with ovulation-inducing hormones.

Estimated rates of monozygotic, dizygotic, trizygotic and tetrazygotic quadruplet deliveries per million were $0.78,0.19,0.04$, and 0.23 , respectively, during the period from 1955 to 1967 and in 1974. The monozygotic quadruplet rate was 2.7 times higher in Japan than in Europe and USA, the dizygotic and tetrazygotic quadruplet rates of the former were a half of the latter, and the trizygotic quadruplet rate of the former was one tenth of the latter.

Stillbirth rates of quadruplets were 0.882 during the period of 1951$1959,0.650$ of $1960-1968$ and 0.607 in 1974, a two-third decrease in around 20 years.

Effects of maternal age and birth order on stillbirth rate of quadruplets were not indicated because of a small sample size.

Effects of gestational age and weight at birth on stillbirth rate were also examined.

\section{INTRODUCTION}

Sawazaki and Tsubata (1976) reported the overall rate of quadruplet births in Japan was 0.93 per million deliveries during the period of 1951-1968. However, there were scarcely data on quadruplet birth rate according to zygosity (Bulmer, 1970)

The present study deals with quadruplet birth rate, both overall and according to zygosity during the period of $1955-1967$ and 1974. It also deals with overall stillbirth rates of quadruplet individuals during the period of 1951-1968 and 1974, where fetal deaths are defined as those after the beginning of the 4th month of fetal life.

Received August 27, 1981 


\section{MATERIALS AND METHODS}

The first source of data is annual volumes of "Vital Statistics of Japan for the Years 1951-1968 and 1974" (Health and Welfare Statistics and Information Department, Ministry of Health and Welfare). The statistics from 1951 to 1968 list the category of survival states of quadruplets: four live-born, three live-born and one still-born, two live-born and two still-born, one live-born and three stillborn, and four still-born. The statistics from 1955 to 1967 provide data on sex compositions of multiple births according to the category of survival states of children. Maternal age are given in the statistics from 1960 to 1968. Second source is "Survey on Socio-Economic Aspects of Vital Events-Plural Births," which provides data on quadruplet births in 1974. Details of the surveys have been reported elsewhere (Imaizumi and Inouye, 1979).

\section{Rate of quadruplet deliveries}

Table 1 lists the number of quadruplet deliveries according to sex composition during the period from 1955 to 1967 and in 1974. Overall rates per million deliveries were 1.14 and 3.29 during the period from 1955 to 1967 and in 1974, respectively, the difference is significant at the $5 \%$ level. From Table 1 numbers of

Table 1. Number of quadruplet deliveries according to sex composition and overall rate, 1955-1967 and 1974.

\begin{tabular}{ccccccccc}
\hline Year & MMMM MMMF & MMFF & MFFF & FFFF & Unknown* & Total & Rate per million \\
\hline 1955 & 1 & 1 & 1 & 0 & 2 & 0 & 5 & \\
1956 & 1 & 0 & 1 & 0 & 1 & 0 & 3 & \\
1957 & 1 & 0 & 0 & 0 & 2 & 0 & 3 & \\
1958 & 1 & 0 & 0 & 0 & 1 & 0 & 2 & \\
1959 & 0 & 0 & 0 & 0 & 0 & 0 & 0 & \\
1960 & 0 & 0 & 0 & 0 & 0 & 1 & 1 & \\
1961 & 2 & 0 & 0 & 0 & 0 & 0 & 2 & \\
1962 & 0 & 0 & 0 & 0 & 1 & 0 & 1 & \\
1963 & 0 & 0 & 0 & 0 & 0 & 0 & 0 & \\
1964 & 2 & 1 & 0 & 1 & 1 & 0 & 5 & \\
1965 & 1 & 0 & 0 & 0 & 0 & 0 & 1 & \\
1966 & 2 & 0 & 0 & 0 & 0 & 0 & 2 & \\
1967 & 1 & 0 & 0 & 0 & 1 & 0 & 2 & \\
Subtotal & 12 & 2 & 2 & 1 & 9 & 1 & 27 & 1.141 \\
1974 & 2 & 2 & 0 & 2 & 0 & 1 & 7 & 3.291 \\
Grand total & 14 & 4 & 2 & 3 & 9 & 2 & 34 & 1.319 \\
\hline
\end{tabular}

* Sex of the one or more is unknwon. 
monozygotic, dizygotic, trizygotic and tetrazygotic quadruplet deliveries were estimated by Allen's method (1960), using sequentially estimated monozygotic and dizygotic twinning, triplet, quadruplet rates, trizygotic triplet and quadruplet rates and so on (Table 2). In applying this method, two quadruplet sets with unknown sex in one or more children were excluded. Since the rate of quadruplet deliveries in 1974 was very high, numbers of sets in each zygosity were estimated for the period either excluding or including 1974. Table 2 also shows the estimated rates of quadruplet deliveries according to zygosity during the same period. For the period excluding 1974, the rates of monozygotic, dizygotic, trizygotic and tetrazygotic quadruplet deliveries per million were $0.80,0.17,0.04$ and 0.09 , respectively, and the corresponding rates for the period including 1974 were $0.78,0.19,0.04$ and 0.23 , respectively. The rates were similar in two calculations except for tetrazygotic quadruplets, the rate of which during the period including 1974 was 2.6 times as high as that during the period excluding 1974.

Table 3 lists the number and rate of quadruplet deliveries according to maternal age during the period from 1960 to 1968 and in 1974 . The rates were 1.49, 1.03, 1.40 and 0 from the youngest to the oldest maternal age groups in this order, and a clear maternal age effect was not indicated.

Table 2. Estimated number and rate of quadruplet deliveries according to zygosity, 1955-1967 and 1974.

\begin{tabular}{cccccc}
\hline \multicolumn{1}{c}{ Year } & Monozygotic & Dizygotic & Trizygotic & Tetrazygotic & Total \\
\hline Excluding 1974 & 19 & 4 & 1 & 2 & 26 \\
Including 1974 & 20 & 5 & 1 & 6 & 32 \\
\hline & \multicolumn{7}{c}{ Number } \\
Excluding 1974 & 0.803 & 0.169 & 0.042 & 0.085 & 1.099 \\
Including 1974 & 0.776 & 0.194 & 0.039 & 0.233 & 1.233 \\
\hline
\end{tabular}

Table 3. Number and rate of quadruplet deliveries according to maternal age, 1960-1968 and 1974.

\begin{tabular}{lcc}
\hline Maternal age & $\begin{array}{c}\text { Total number of } \\
\text { deliveries }\end{array}$ & Rate per million \\
\hline Under 25 & 8 & 1.490 \\
$25-29$ & 9 & 1.033 \\
$30-34$ & 5 & 1.399 \\
Over 35 & 0 & - \\
Total & 22 & 1.177 \\
\hline
\end{tabular}

Vol. 27, No. 3, 1982 
Stillbirth rate of quadruplets

Table 4 shows the number of quadruplet deliveries according to survival states during the period from 1951 to 1968 and in 1974 . In the following analysis, stillbirth rate of quadruplets was computed among total quadruplet individuals. The stillbirth rate of quadruplet individuals was the highest during the earlier period $(0.882)$, followed by the next period $(0.650)$, and the lowest in the recent year $(0.607)$.

Table 5 shows the number of quadruplet individuals according to survival states and sex during the period from 1955 to 1968 and in 1974 . The stillbirth rates of quadruplet individuals were 0.692 and 0.777 for males and females, respectively, but the difference was not significant.

Table 6 lists the number of like-sexed and unlike-sexed sets according to sur-

Table 4. Number of quadruplet deliveries according to survival states and stillbirth rate of quadruplet individuals, 1951-1968 and 1974.

\begin{tabular}{cccccccc}
\hline Year & $4 \mathrm{LB}$ & $\begin{array}{c}3 \mathrm{LB} \\
\text { 1SB }\end{array}$ & $\begin{array}{c}\text { 2LB } \\
\text { 2SB }\end{array}$ & $\begin{array}{c}1 \text { LSB } \\
\text { 3SB }\end{array}$ & $\begin{array}{c}\text { 4SB } \\
\text { Stillbirth rate }\end{array}$ \\
\hline 1951 & 0 & 0 & 0 & 0 & 0 & 0 & \\
1952 & 1 & 0 & 0 & 0 & 1 & 2 & \\
1953 & 0 & 0 & 0 & 0 & 0 & 0 & \\
1954 & 0 & 0 & 0 & 0 & 2 & 2 & \\
1955 & 0 & 0 & 1 & 0 & 4 & 5 & \\
1956 & 0 & 0 & 1 & 0 & 2 & 3 & \\
1957 & 0 & 0 & 0 & 0 & 3 & 3 & \\
1958 & 0 & 0 & 0 & 0 & 2 & 2 & \\
1959 & 0 & 0 & 0 & 0 & 0 & 0 & \\
Subtotal & 1 & 0 & 2 & 0 & 14 & 17 & 0.8824 \\
\hline 1960 & 0 & 0 & 0 & 0 & 1 & 1 & \\
1961 & 1 & 0 & 0 & 0 & 1 & 2 & \\
1962 & 0 & 1 & 0 & 0 & 0 & 1 & \\
1963 & 0 & 0 & 0 & 0 & 0 & 0 & \\
1964 & 1 & 0 & 1 & 0 & 3 & 5 & \\
1965 & 0 & 0 & 0 & 0 & 1 & 1 & \\
1966 & 0 & 0 & 0 & 0 & 2 & 2 & 0.6071 \\
1967 & 1 & 0 & 0 & 0 & 1 & 2 & \\
1968 & 1 & 0 & 0 & 0 & 0 & 1 & \\
Subtotal & 4 & 1 & 1 & 0 & 9 & 15 & 0.6500 \\
\hline 1974 & 2 & 0 & 1 & 1 & 3 & 7 & \\
\hline Grand total & 7 & 1 & 4 & 1 & 26 & 39 & \\
\hline
\end{tabular}

LB, live-born; SB, still-born. 
Table 5. Number of live-births and stillbirths and stillbirth rate of quadruplet individuals according to sex, 1955-1968 and 1974.

\begin{tabular}{|c|c|c|c|c|c|c|c|c|c|}
\hline \multirow{2}{*}{ Year } & \multicolumn{2}{|c|}{ Live-birth } & \multicolumn{3}{|c|}{ Stillbirth } & \multirow{2}{*}{ Total } & \multicolumn{3}{|c|}{ Stillbirth rate } \\
\hline & Males & Females & Males & Females & Unknown & & Males & Females & Total \\
\hline $1955-1968$ & 17 & 8 & 45 & 38 & 4 & 112 & 0.7258 & 0.8261 & 0.7768 \\
\hline 1974 & 7 & 4 & 9 & 4 & 4 & 28 & 0.5625 & 0.5000 & 0.6071 \\
\hline Total & 24 & 12 & 54 & 42 & 8 & 140 & 0.6923 & 0.7778 & 0.7429 \\
\hline
\end{tabular}

Table 6. Numbers of like- and unlike-sexed quadruplet sets according to survival states and stilloirth rate of quadruplet individuals, 1955-1968 and 1974.

\begin{tabular}{|c|c|c|c|c|c|c|c|c|c|c|c|c|c|c|}
\hline \multirow{2}{*}{ Year } & \multicolumn{7}{|c|}{ Like-sexed } & \multicolumn{7}{|c|}{ Unlike-sexed } \\
\hline & $4 \mathrm{LB}$ & $\begin{array}{l}\text { 3LB } \\
1 \mathrm{SB}\end{array}$ & $\begin{array}{l}2 \mathrm{LB} \\
2 \mathrm{SB}\end{array}$ & $\begin{array}{l}1 \mathrm{LB} \\
3 \mathrm{SB}\end{array}$ & $4 \mathrm{SB}$ & Total & $\begin{array}{l}\text { Stillbirth } \\
\text { rate }\end{array}$ & $4 \mathrm{LB}$ & $\begin{array}{l}3 \mathrm{LB} \\
1 \mathrm{SB}\end{array}$ & $\begin{array}{l}2 \mathrm{LB} \\
2 \mathrm{SB}\end{array}$ & $\begin{array}{l}1 \mathrm{LB} \\
\text { 3SB }\end{array}$ & $4 \mathrm{SB}$ & Total & $\begin{array}{l}\text { Stillbirth } \\
\text { rate }\end{array}$ \\
\hline $1955-1968$ & 3 & 1 & 3 & 0 & 14 & 21 & 0.7500 & 1 & 0 & 0 & 0 & 5 & 6 & 0.8333 \\
\hline 1974 & 1 & 0 & 0 & 0 & 1 & 2 & 0.5000 & 1 & 0 & 1 & 1 & 1 & 4 & 0.5625 \\
\hline Total & 4 & 1 & 3 & 0 & 15 & 23 & 0.7283 & 2 & 0 & 1 & 1 & 6 & 10 & 0.7250 \\
\hline
\end{tabular}

LB, live-born; SB, still-born.

Table 7. Number and rate of stillbirths of quadruplet individuals in like- and unlike-sexed sets according to maternal age, 1960-1968 and 1974.

\begin{tabular}{|c|c|c|c|c|c|c|c|c|}
\hline \multirow{2}{*}{$\begin{array}{c}\text { Maternal } \\
\text { age }\end{array}$} & \multicolumn{8}{|c|}{ Like-sexed } \\
\hline & $4 \mathrm{LB}$ & $\begin{array}{l}3 \mathrm{LB} \\
1 \mathrm{SB}\end{array}$ & & & $\begin{array}{l}1 \mathrm{LB} \\
3 \mathrm{SB}\end{array}$ & $4 \mathrm{SB}$ & Total & $\begin{array}{l}\text { Stillbirth } \\
\text { rate }\end{array}$ \\
\hline Under 25 & 1 & 1 & & 1 & 0 & 3 & 6 & 0.6250 \\
\hline $25-29$ & 2 & 0 & & 0 & 0 & 2 & 4 & 0.5000 \\
\hline $30-34$ & 1 & 0 & & 0 & 0 & 2 & 3 & 0.6667 \\
\hline Over 35 & 0 & 0 & & 0 & 0 & 0 & 0 & - \\
\hline Total & 4 & 1 & & 1 & 0 & 7 & 13 & 0.5962 \\
\hline \multirow{2}{*}{$\begin{array}{c}\text { Maternal } \\
\text { age }\end{array}$} & \multicolumn{7}{|c|}{ Unlike-sexed } & \multirow{2}{*}{$\frac{\text { Unknown* }}{4 \mathrm{SB}}$} \\
\hline & $4 \mathrm{LB}$ & $\begin{array}{l}3 \mathrm{LB} \\
1 \mathrm{SB}\end{array}$ & $\begin{array}{l}2 \mathrm{LB} \\
2 \mathrm{SB}\end{array}$ & $\begin{array}{l}1 \mathrm{LB} \\
3 \mathrm{SB}\end{array}$ & $4 \mathrm{SB}$ & Total & $\begin{array}{l}\text { Stillbirth } \\
\text { rate }\end{array}$ & \\
\hline Under 25 & 1 & 0 & 1 & 0 & 0 & 2 & 0.2500 & 0 \\
\hline $25-29$ & 0 & 0 & 0 & 1 & 3 & 4 & 0.9375 & 1 \\
\hline $30-34$ & 1 & 0 & 0 & 0 & 0 & 1 & 0 & 1 \\
\hline Over 35 & 0 & 0 & 0 & 0 & 0 & 0 & - & 0 \\
\hline Total & 2 & 0 & 1 & 1 & 3 & 7 & 0.6071 & 2 \\
\hline
\end{tabular}

* Sex of the one or more is unknown.

Vol. 27, No. 3, 1982 
Table 8. Place of birth, sex composition, survival state, maternal age and gestational age in seven quadruplet deliveries, 1974.

\begin{tabular}{llccc}
\hline Place of birth & $\begin{array}{c}\text { Sex } \\
\text { composition }\end{array}$ & $\begin{array}{c}\text { Survival state } \\
\text { at birth* }\end{array}$ & $\begin{array}{c}\text { Maternal age } \\
\text { (years) }\end{array}$ & $\begin{array}{c}\text { Gestational age } \\
\text { (months) }\end{array}$ \\
\hline Saitama & FFFM & LSSS & 25 & 8 \\
Saitama & FFMF & LLSS & 24 & 8 \\
Tokyo & MMMF & SSSS & 25 & 8 \\
Tokyo & MFMM & LLLL & 32 & 8 \\
Shizuoka & MMMM & LLLL & 32 & 10 \\
Aichi & UUUU & SSSS & 25 & 5 \\
Aichi & MMMM & SSSS & 24 & 5 \\
\hline
\end{tabular}

* L, Live-born; S, still-born.

vival states at birth during the period from 1955 to 1968 and in 1974 . The stillbirth rates of quadruplet individuals were 0.728 in like-sexed sets and 0.725 in unlikesexed sets.

Table 7 lists the number of fetal deaths in like- and unlike-sexed sets according to maternal age during the period from 1960 to 1968 and in 1974, from which were computed stillbirth rates of quadruplets in like- and unlike-sexed sets according to maternal age. In like-sexed quadruplets the stillbirth rate remained almost constant in each maternal age group.

Table 8 shows place of birth, sex composition, survival state at birth, maternal age and gestational age of seven quadruplets born in 1974. From this table a tendency is seen that stillbirth rate increases in later birth orders.

Birth weight of 20 quadruplet individuals born in 1974 and their survival states at birth are provided in Table 3 of the previous report (Asaka et al., 1980). From this table stillbirth rates were $0.8(8 / 10)$ for the birth weight less than or equal to $1,000 \mathrm{~g}, 0.143(1 / 7)$ for birth weight between $1,000 \mathrm{~g}$ and $2,000 \mathrm{~g}$ and $0(0 / 3)$ for birth weight more than $2,000 \mathrm{~g}$, respectively.

\section{DISCUSSION}

The rate of quadruplet deliveries in 1974 was three times as high as that of the period from 1955 to 1967 (Table 1). According to Sawazaki and Tsubata (1976), ovulation-inducing hormone has been used in Japan since 1966. Therefore the higher quadruplet birth rate in 1974 might be attributed to higher proportion of mothers treated with ovulation-inducing hormones.

According to Bulmer (1970), monozygotic, dizygotic, trizygotic and tetrazygotic quadruplet rates per million deliveries were $0.29,0.43,0.42$ and 0.56 , respectively for the combined data from England and Wales, U.S.A., France and Italy, whereas the corresponding rates in the present study were $0.78,0.19,0.04$ and 0.23 , respec- 
tively (Table 2). The monozygotic quadruplet rate was 2.7 times higher in Japan than in Europe and U.S.A., the dizygotic and the tetrazygotic quadruplet rates of the former were a half of the latter, and the trizygotic quadruplet rate of the former was one tenth of the latter. According to Imaizumi and Inouye (1979), monozygotic twinning rate in Japan was similar to that in other countries (also see Bulmer, 1970). However, monozygotic triplet rate in Japan was around two times higher than other countries (England and Wales, U.S.A., Italy, and Australia), and dizygotic and trizygotic triplet rates of the former were one third to one fourth and one sixth to one thirteenth of the latter, respectively (Imaizumi and Inouye, 1980a). Although the sample size both in Bulmer's report and in the present study is small, it seems that a characteristic feature of multiple birth rate in Japan is higher rates of triplets and quadruplets of polyembryonal origin and lower rates of those of polyovulational origin than Caucasian populations.

According to Bulmer (1970), rate of quadruplets increased with maternal age, but in the present study a clear maternal age effect was not indicated because of scarce of data on triplet births (Table 3).

According to Imaizumi et al. (1980), and Imaizumi and Inouye (1980b), stillbirth rates of twins and triplets were decreased with the year during the period of 19511968 and in 1974. The stillbirth rate in 1974 was decreased to a half $(0.123)$ for twins and two-third (0.379) for triplets during the past 23 years. Similarly, stillbirth rates of quadruplets were 0.882 during the period of 1951-1959, 0.650 of 1960-1968 and 0.607 in 1974, a two-third decreased in around 20 years (Table 4). On the other hand, stillbirth rate in the general population in 1974 was 0.051 , and stillbirth rates of twins, triplets and quadruplets were still $2.4,7.4$ and 11.8 times as high as that of the general population.

Stillbirth rate was higher in males than females for twins (Imaizumi et al., 1980) and triplets (Imaizumi and Inouye, 1980b), but in quadruplets it was higher in females (0.778) than males (0.692) (Table 5), but the difference was not significant.

Maternal age effect on stillbirth rate of quadruplets was not indicated in the present study (Table 7).

There may exist a birth order effect on stillbirth rate of quadruplets (Table 8), but because of small sample size it is yet to be confirmed.

\section{REFERENCES}

Allen, G. 1960. A differential method for estimation of type frequencies in triplets and quadruplets. Am. J. Hum. Genet. 12: 210-224.

Asaka, A., Imaizumi, Y., and Inouye, E. 1980. Analysis of multiple births in Japan. II. Weight at birth of triplets and quadruplets. Jpn. J. Human Genet. 25: 207-211.

Bulmer, M.G. 1970. The Biology of Twinning in Man. Clarendon Press, Oxford.

Imaizumi, Y., and Inouye, E. 1979. Analysis of multiple birth rates in Japan. I. Secular trend, maternal age effect, and geographical variation in twinning rates. Acta Genet. Med. Gemellol. 28: $107-124$. 
Imaizumi, Y., Asaka, A., and Inouye, E. 1980. Analysis of multiple birth rates in Japan. II. Secular trend, and effect of birth order, maternal age and gestational age in stillbirth rate of twins. Acta Genet. Med. Gemellol. 29 : 223-231.

Imaizumi, Y., and Inouye, E. 1980a. Analysis of multiple birth rates in Japan. III. Secular trend, maternal age effect and geographical variation in triplet rates. Jpn. J. Human Genet. 25: 73-81.

Imaizumi, Y., and Inouye, E. 1980b. Analysis of multiple birth rates in Japan. IV. Secular trend, effect of maternal age and gestational age in stillbirth rates of triplets. Jpn. J. Human Genet. 25: 219-227.

Japan, Ministry of Health and Welfare. Annual, 1951-1968 and 1974. Vital Statistics, Health and Welfare Statistics and Information Department, Ministry of Health and Welfare, Tokyo.

Japan, Ministry of Health and Welfare. 1977. Survey on Socio-economic Aspects of Vital EventsPlural Births, 1975. Health and Welfare Statistics and Information Department, Ministry of Health and Welfare, Tokyo.

Sawazaki. C., and Tsubata, H. 1976. Statistics of multiple births in Japan. Sanka to Fujinka 43: $863-869$ (in Japanese). 